Article

\title{
An Integrated Membrane Process for Butenes Production
}

\author{
Leonardo Melone, Adele Brunetti, Enrico Drioli and Giuseppe Barbieri * \\ Institute on Membrane Technology (ITM-CNR), National Research Council c/o, The University of Calabria, \\ Cubo 17C, Via Pietro BUCCI, 87036 Rende CS, Italy; 1.melone@itm.cnr.it (L.M.); a.brunetti@itm.cnr.it (A.B.); \\ e.drioli@itm.cnr.it (E.D.) \\ * Correspondence: g.barbieri@itm.cnr.it; Tel.: +39-0984-492029
}

Academic Editor: Fausto Gallucci

Received: 11 August 2016; Accepted: 8 November 2016; Published: 15 November 2016

\begin{abstract}
Iso-butene is an important material for the production of chemicals and polymers. It can take part in various chemical reactions, such as hydrogenation, oxidation and other additions owing to the presence of a reactive double bond. It is usually obtained as a by-product of a petroleum refinery, by Fluidized Catalytic Cracking (FCC) of naphtha or gas-oil. However, an interesting alternative to iso-butene production is $n$-butane dehydroisomerization, which allows the direct conversion of $n$-butane via dehydrogenation and successive isomerization. In this work, a simulation analysis of an integrated membrane system is proposed for the production and recovery of butenes. The dehydroisomerization of $n$-butane to iso-butene takes place in a membrane reactor where the hydrogen is removed from the reaction side with a $\mathrm{Pd} / \mathrm{Ag}$ alloys membrane. Afterwards, the retentate and permeate post-processing is performed in membrane separation units for butenes concentration and recovery. Four different process schemes are developed. The performance of each membrane unit is analyzed by appropriately developed performance maps, to identify the operating conditions windows and the membrane permeation properties required to maximize the recovery of the iso-butene produced. An analysis of integrated systems showed a yield of butenes higher than the other reaction products with high butenes recovery in the gas separation section, with values of molar concentration between $75 \%$ and $80 \%$.
\end{abstract}

Keywords: integrated process; membranes; iso-butene production

\section{Introduction}

Nowadays, the great demand for increased energy and fine chemicals species has pushes the industry towards more sustainable production and development. Process Intensification (PI) Strategy [1] has acquired an important role in the industrial development, pursuing volume reduction of devices and plant, minimization of energy demand and better raw materials exploitation [2]. The challenge of membrane engineering is to redesign production processes in the logic of PI and this can also be successfully applied in the petrochemical industry. The annual world production of butenes reached 132 million tons [3]. In particular, iso-butene is the most important butene isomer because it is used in many syntheses, such as butyl rubbers and additives for gasoline (e.g., Methyl tert-butyl ether) production.

Today, the most widespread process for butenes production is FCC. A hydrocarbon stream is fed into the FCC unit and an olefins-rich stream is recovered as a product stream. This process produces $70 \%$ of the world butenes supply. Another important process for butenes production is steam cracking, which satisfies $26 \%$ of the world demand. Only $4 \%$ of butenes is produced by dehydrogenation and dehydroisomerization of the butane. The latter technologies are very important in PI logic since they produce specific butenes, e.g., iso-butene. Conversely, the aim of FCC and steam cracking is ethylene 
and propylene production and the butenes are only reaction by-products. The dehydroisomerization system, instead, uses two different reactors in series. The first unit allows the dehydrogenation of the butane, and then the downstream of the reactor containing butenes is fed into the second reactor. Here, the butenes become specific butene isomers, for example iso-butene. Today, four industrial processes are used for butane conversion to butenes. The Oleflex process developed by UOP uses a fluidized bed reactor operated at 2 bar and variable temperature in the range $580-650{ }^{\circ} \mathrm{C}$. STAR, Clariant and Linde-BASF, instead, use packed bed reactors in the same temperature range as the Oleflex process. In particular, the STAR system operates at 5 bar, whereas, the Clariant and Linde-BASF operate at a reaction pressure of $0.3-0.5$ bar and 1 bar, respectively [3].

An interesting alternative to the two-step processes [4] is a direct one-step process, allowing the direct conversion of $n$-butane to iso-butene [5,6]. Recently, various bi-functional catalytic systems were reported in the literature, usually considering Pt supported zeolites, as successful catalysts for such direct conversion [7,8]. Meanwhile, the use of membrane reactors (MRs) was proposed. This integrated approach, which combines the reaction and separation in a single unit, fits the targets of Process Intensification well $[9,10]$. Furthermore, the possibility of exceeding the equilibrium constraint of traditional reactors (TRs) in reversible reactions such as dehydrogenations is quite appealing [11]. For dehydrogenation-type reactions, the application of MRs, where hydrogen can be removed with high selectivity from the reaction mixture, is an interesting strategy. For these reactions, thermodynamically favored by low temperature, the removal of a product shifts equilibrium, improving the conversion significantly. Various researchers reported on iso-butane dehydrogenation using catalytic MRs [12-14] considering many types of membranes [15] such as $\gamma$-alumina, zeolite MFI, Pd/Ag and Pd, dense silica and carbon molecular sieve membranes [16-19]. In most of their studies a conversion above the equilibrium one of a TR was obtained owing to hydrogen removal through the membrane.

In particular, the Pd-based membrane, owing to its infinite selectivity toward hydrogen, promotes the recovery of pure hydrogen not requiring further separation steps. Moreover, its removal from the reaction volume shifts the equilibrium conversion according to the Le Chatelier principle. MR equilibrium conversion was evaluated by Marigliano et al. [20], Brunetti et al. [21] and Barbieri et al. [22] taking into account chemical reaction equilibrium and permeative equilibrium through the membrane. They used a reactor in series model to describe the equilibrium of an ideal Pd-based MR for methane steam reforming, adding an extra constraint which takes into account the permeative equilibrium. A similar approach was used by Al Megren et al. [23] for the $n$-butane dehydroisomerization reaction in a wide range of temperatures, reaction pressures and equilibrium hydrogen partial pressures, by means of a simplified reaction scheme. This analysis showed that the membrane reactor equilibrium conversion (MREC) achievable in a Pd-Ag MR can be up to seven times greater than the TR one, operated in the same conditions.

An important issue in olefins production is their separation, usually performed by cryogenic distillation or PSA [24]; thus, the cost of the separation takes ca. 70\% of the total capital. Membrane technology can be a valuable alternative to these technologies owing to its modularity, simplicity, lower costs, etc. Membranes will fit in well in the PI strategy and their use is becoming more and more important also in the petrochemical industry [11-13]. Various papers in the open literature refer to the use of polymeric membranes for the separation of hydrocarbons; Pinnau et al. [25] proposed the use of PTMSP membranes for the separation of $n$-butanes from light species (hydrogen and nitrogen). Sakellaropoulos et al. [26] showed the applicability of the Matrimid membrane in $\mathrm{C}_{4}$ hydrocarbon separation. Yang et al. [27] and Adachi et al. [28] used mixed matrix membranes (MMMs) with $\mathrm{Ag}^{+}$ ions for olefins separation.

In this work, a simulation study of an integrated membrane system is proposed for the production and recovery of butenes. The dehydroisomerization of $n$-butane to iso-butene takes place in a $\mathrm{Pd} / \mathrm{Ag}$ MR whose permeate is pure in $\mathrm{H}_{2}$ while the retentate is then treated in a membrane gas separation system for butenes concentration and recovery. 
Four different process schemes (cases studies) are proposed considering the use of polymeric gas separation membrane units for downstream processing. The performance of each membrane unit is analyzed by appropriately developed performance maps, to identify the operating conditions windows and the membrane permeation properties required to maximize the recovery of the iso-butene produced.

\section{Materials and Methods}

The process scheme for butenes production and separation is shown in Figure 1. The first block "MR" is the membrane reactor equipped with a Pd-Ag membrane. This stage is used for converting $n$-butane to butenes, recovering, in the meantime, the hydrogen produced through the Pd-Ag membrane. A membrane gas separation system "GS" is the second block used for the separation of butenes from the other species, such as methane, ethane and hydrogen contained in the retentate stream exiting the MR. The driving force necessary for the permeation is promoted by pressurizing the MR upstream. Considering negligible pressure drop along the MR, the retentate stream is at the same pressure as the feed. In addition, for the GS, the pressure drop is negligible along the membrane gas separation units [29].

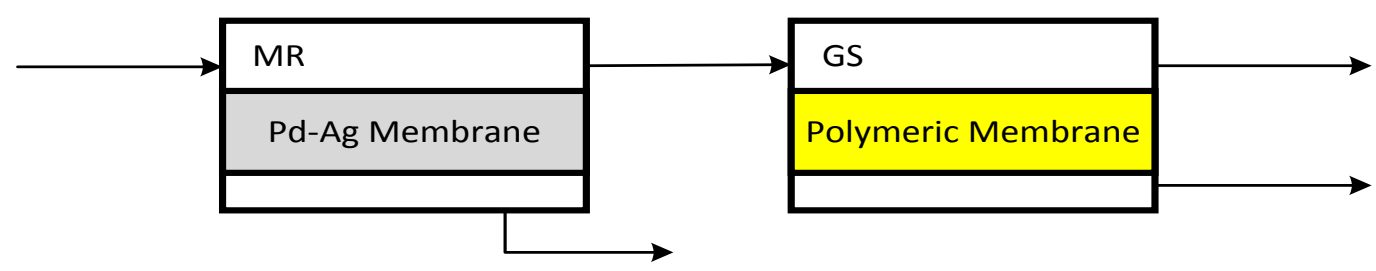

Figure 1. Membrane process scheme.

\subsection{Membrane Reactor}

The membrane reactor contains a Pd-Ag membrane for the selective separation of hydrogen during the $n$-butane dehydroisomerization reaction (Figure 2). The MR has a tube-in-tube configuration with the internal tube being the Pd-Ag membrane, infinitively selective toward $\mathrm{H}_{2}$, the external is the reactor shell. The reactants are fed in the annulus between the internal surface of the shell and the external surface of the membrane, where the catalyst is present in a packed bed configuration. The retentate stream is recovered on the same side as the feed; the hydrogen permeated through the membrane is recovered in the membrane inner side.

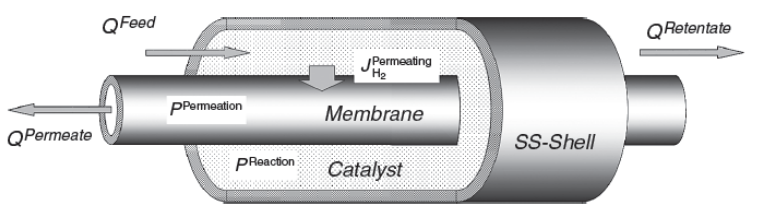

Figure 2. Membrane reactor scheme.

The $n$-butane dehydroisomerization is an endothermic reaction with mole number increasing [6]; therefore, it is favored by high temperature and low pressure. The reaction is schematically represented in two steps: the first step (Equation (1)) being the dehydrogenation of $n$-butane to $n$-butene and hydrogen; and the second (Equation (2)), the $n$-butene isomerization to iso-butene.

$$
\begin{array}{lrl}
\Delta \widetilde{H}_{\text {reaction }}\left(25^{\circ} \mathrm{C}\right)=130 \frac{\mathrm{kJ}}{\mathrm{mol}} & \Delta \widetilde{H}_{\text {reaction }}\left(25^{\circ} \mathrm{C}\right)=130 \frac{\mathrm{kJ}}{\mathrm{mol}} \\
n-\text { Butene } \rightleftarrows \text { iso }- \text { Butene } & \Delta \widetilde{H}_{\text {reaction }}\left(25^{\circ} \mathrm{C}\right)=-17 \frac{\mathrm{kJ}}{\mathrm{mol}}
\end{array}
$$


In a Pd-Ag MR, the continuous removal of hydrogen from the reaction volume drives the reaction toward further $n$-butane conversion promoting butene formation. The mass balances of the dehydroisomerization reaction carried out in the Pd-Ag MR are summarized in Table 1 [23]. Hydrogen was considered in the feed stream to replace the inert gas in the feed stream as reported in paper of Al-Megren et al. [23]. Therefore, the permeation membrane load is significantly higher in the present study. $n_{0}$ is the initial $n$-butane moles; $m$ is the initial mole ratio between hydrogen and $n$-butane; $x_{1}$ is the $n$-butane conversion for dehydrogenation (Equation (1)) and $x_{2}$ the $n$-butene conversion for isomerization (Equation (2)); hydrogen permeation is accounted for by $z$.

The thermodynamics analysis was carried out for reactive and permeative equilibrium in the MR [20]. The permeative equilibrium occurs when the net hydrogen flux through the membrane is zero so the hydrogen partial pressure of the retentate equals the permeate one (Equation (3)). Marigliano et al. [20] demonstrated how MREC strongly depends on hydrogen equilibrium partial pressure and its effect is more significant than reaction pressure, promoting the conversion even though the reaction is thermodynamically unfavorable.

$$
P_{\mathrm{H}_{2} \text {,equilibrium }}^{\text {Permeate }}=P_{\mathrm{H}_{2} \text {,equilibrium }}^{\text {Retentate }}
$$

Table 1. Stoichiometric table for the reactive and permeative equilibrium in a membrane reactor.

\begin{tabular}{cccccc}
\hline \multicolumn{7}{c}{ Moles Number } \\
\hline & $n$-Butane & Hydrogen & $n$-Butene & iso-Butene & Inert \\
\hline Initial value & $n_{0}$ & $n_{0} \cdot m$ & - & - & $n_{\text {Inert }}$ \\
Reaction I & $-n_{0} x_{1}$ & $n_{0} x_{1}$ & $n_{0} x_{1}$ & - & - \\
Reaction II & - & - & $-n_{0} x_{1} x_{2}$ & $n_{0} x_{1} x_{2}$ & - \\
Permeation & - & $-n_{0}\left(m+x_{1}\right) z$ & - & - & - \\
Equilibrium state & $n_{0}\left(1-x_{1}\right)$ & $n_{0}\left(m+x_{1}\right)(1-z)$ & $n_{0} x_{1}\left(1-x_{2}\right)$ & $n_{0} x_{1} x_{2}$ & - \\
Total moles & & $n_{0}[1+m+x 1-m z]+n_{\text {Inert }}$ & & \\
\hline
\end{tabular}

The equilibrium balance (of a TR) is directly deductible from the MR one, when not accounting for the permeation term $(z)$, which is zero in the TR system. Equations (4) and (5) are the equilibrium reaction constant, as a function of temperature and in terms of the species molar fraction.

$$
\begin{aligned}
& K_{\text {equilibrium }, 1}(T)=5.7110^{7} \mathrm{e}^{\frac{-15.810^{3}}{T}}=\frac{n_{\mathrm{H}_{2}} n_{n-\mathrm{C}_{4} \mathrm{H}_{8}}}{n_{\text {total }} n_{n-\mathrm{C}_{4} \mathrm{H}_{10}}} P^{\text {Reaction }} \\
&=\frac{x_{1}\left(m+x_{1}\right)(1-z)\left(1-x_{2}\right)}{\left(1-x_{1}\right)\left(1+m+x_{1}-m z+\frac{n_{\text {Inert }}}{n_{0}}\right)} P^{\text {Reaction }} \\
& K_{\text {equilibrium, }, 2}(T)=0.207 \mathrm{e}^{\frac{1936}{T}}=\frac{n_{\text {iso }-\mathrm{C}_{4} \mathrm{H}_{8}}}{n_{n-\mathrm{C}_{4} \mathrm{H}_{8}}}=\frac{x_{2}}{1-x_{2}}
\end{aligned}
$$

It was chosen to operate the reaction at $550{ }^{\circ} \mathrm{C}$, as a good compromise between the positive effect on reaction thermodynamics and kinetics and the Pd-Ag membrane typical operating range [30]. Therefore, Table 2 reports the values at $550{ }^{\circ} \mathrm{C}$ selected from the Figure 1 of Inaba et al. [31]. Ten bar was the maximum pressure used in the different schemes, as it allows low operating and a fixed cost of the compressor. Two different feeds were considered:

(1) An equimolecular mixture of $n$-butane and nitrogen, as in the Al Megren et al. [23] work.

(2) A $n$-butane/hydrogen mixture, as in the thermodynamics analysis reported below.

A pressure of 0.1 bar is uncommon in industrial processes; however, some industrial plants, such as the Clariant one, operate at a reaction pressure of $0.3-0.5$ bar. Therefore, a permeate pressure or hydrogen equilibrium pressure of 0.1 bar was coupled to a reaction pressure of 1.5 or 10 bar. Sweep gas can be also used for keeping the hydrogen partial pressure low. 
The $n$-butane conversion was calculated for the equilibrium condition at all the temperatures and pressures investigated. In particular, MR conversion of Cases 1, 3 and 4 refer to the data reported by Al-Megren et al. [23]. A lower and conservative value equal to $90 \%$ of the equilibrium value was used as the actual conversion of the MR. Then, the selectivities reported in Table 2 were used to evaluate the composition of the MR outlet stream. This procedure was applied since the work was aimed to investigate the process as whole and it was not specifically devoted to the modeling of MRs.

Liang et al. [18], by using Pd-based MR, demonstrated that an undesirable formation of heavy alkane products on the membrane surface does not take place. Thus, the reaction selectivities of Inaba et al. [31] were considered as reference. Table 2 reports the values measured at $550{ }^{\circ} \mathrm{C}$, over the Cr/H-SSZ-35 catalyst.

Table 2. Reactor selectivities for the $n$-butane conversion [31].

\begin{tabular}{lccccccc}
\hline \multirow{2}{*}{ Component } & $\mathrm{C}_{1}-\mathrm{C}_{3}$ & \multicolumn{7}{c}{$\mathrm{C}_{4}$} \\
\cline { 3 - 8 } & & iso-Butane & 1-Butene & iso-Butene & trans-2-Butene & cis-2-Butene & 1,3-Butadiene \\
\hline \multirow{2}{*}{ Selectivity } & \multirow{2}{*}{0.26} & 0.02 & 0.11 & 0.24 & 0.2 & 0.11 & 0.06 \\
\cline { 3 - 8 } & & \multicolumn{7}{c}{0.74} \\
\hline
\end{tabular}

\subsection{Separation System}

The multistage gas separation membrane system was simulated by means of performance maps developed by Brunetti et al. [32] and appropriately calculated for the objectives of this work. The model used for developing these maps consists of a 1D dimensionless model for the mixture species in steady-state conditions. More details can be found in [32]. The performance maps are described in terms of two important dimensionless groups: the permeation number $\theta_{A}$ (Equation (6)) and the pressure ratio $\phi$ (Equation (7)).

$$
\begin{gathered}
\theta_{A}=\frac{\text { Permeance }_{A} A^{\text {Membrane }} P^{\text {Permeate }}}{x_{A}^{\text {Feed }} Q^{\text {Feed }}} \\
\phi=\frac{P^{\text {Feed }}}{P^{\text {Permeate }}}
\end{gathered}
$$

The permeation number expresses a comparison between the two main mass transport mechanisms involved: permeation through the membrane and convective transport at the membrane inlet. A high permeation number corresponds to a high residence time of the stream, meaning low permeation through the membrane. The pressure ratio is an index of the maximum permeation driving force for permeation. For given feed composition, membrane properties, module geometry and operating conditions, the solution of the equations system provides the dimensionless flow rate profile for each species. The concentration profile for each species and the recovery in a specific stream (Figure 3) are obtained from these profiles.

Figure 3 shows an example of a typical performance map of a membrane gas separation unit developed in this work where the butenes molar fraction is reported against butenes recovery at the permeate side of the membrane unit. Each point of these curves is a specific membrane system characterized by its own operating conditions, feed compositions, etc. All curves (black line) are obtained for a constant value of pressure ratio and show the same trend: the butenes concentration at the permeate side increases as the butenes recovery increases as well. The blue line was drawn for different pressure ratios and the same permeation number. At a given permeation number, the butenes concentration increases when the pressure ratio decreases.

The operating conditions, in term of pressure ratio and permeation number, were chosen according to the required composition of the permeate stream. All the permeate streams are less concentrated in the more permeable species at higher permeation number values. The lower the pressure ratio, the higher the concentration of the less permeable species (the butanes permeability is lower compared 
to hydrogen). The permeation number and pressure ratio were discussed in detail along with the case studies. The traditional separation system was also simulated, with Aspen Hysys®software (Aspen Technology, Inc, Burlington, VT, USA), as reference case considering the use of a flash for separating a hydrocarbon liquid fraction. The reactor outlet stream has to be cooled before entering the membrane units; however, polymeric membranes operate at $30-60{ }^{\circ} \mathrm{C}$ and also not in a cryogenic range. The flash unit operating on the cooled stream, although it cannot separate it into pure species, it can split this stream into two streams with significantly different composition.

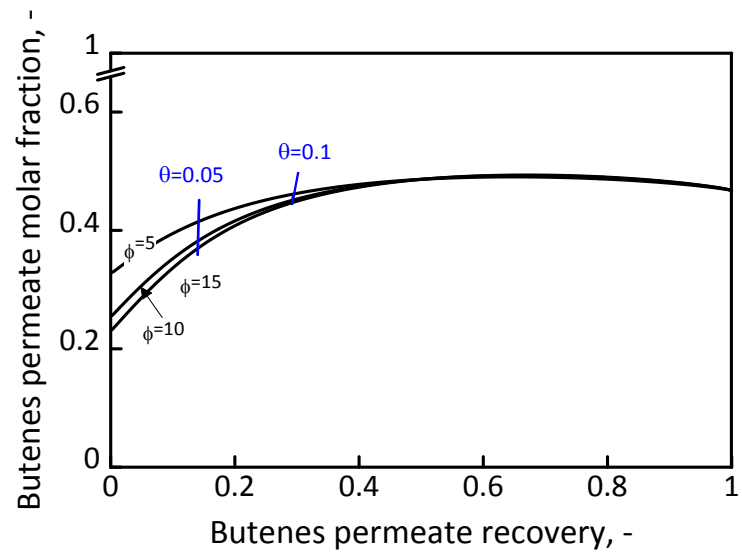

Figure 3. Butenes permeate molar fraction as a function of butenes permeate recovery for different pressure ratio and permeation number.

\section{Results}

\subsection{Membrane Reactor for $n$-Butane Conversion}

Figure 4 shows the MREC (red line) and TREC (black line) as a function of the temperature for different reaction pressures. The analysis was carried out for an $n$-butane/hydrogen feed mixture, with 0.80 initial molar fraction of $n$-butane. The thermodynamics of the equimolecular mixture of $n$-butane and $\mathrm{N}_{2}$ was already analyzed by Al Megren et al. [23] keeping the hydrogen equilibrium partial pressure always at 0.1 bar. As mentioned, the $n$-butane dehydroisomerization is an endothermic reaction that occurs with an increase of mole number; therefore, it is favored by a high temperature and a low pressure. As shown in Figure 4, equilibrium conversions of both MR and TR increased with temperature. However, the negative effect of pressure appeared quite evident on TR conversion. For instance, at $550{ }^{\circ} \mathrm{C}$, the TR conversion was around 0.3 at a reaction pressure of 5 bar, but it decreased down to 0.21 for a pressure of 10 bar. Conversely, the MREC does not depend on reaction pressure (Figure 4) for an equilibrium hydrogen partial pressure of 0.1 bar. Figure 4 shows, at the operating conditions considered, that MREC was always higher than TREC, owing to the hydrogen permeation through the Pd-Ag membrane which promoted the $n$-butane equilibrium conversion, by removing a product from reaction volume.

The MREC/TREC ratio, used for estimating the improvement of MR with respect to TR, identifies two different regions: one above and one below. In the first (yellow fill), the MREC was higher than TREC (MREC/TREC > 1) because of the good effect of the hydrogen removal from the reaction side. In the second (cyan fill), TREC is higher than MREC (MREC/TREC < 1) since the back-permeation causes a higher hydrogen concentration in the MR than that in the TR and, consequently, a conversion reduction. The operating condition chosen in this work limited the analysis in the first region. For instance, the MREC was significantly higher than TREC (MREC/TREC > 30, Figure 5) at 20 bar and temperature lower than $450{ }^{\circ} \mathrm{C}$. As the temperature increased, the MREC/TREC ratio tended to 1. At temperatures higher than $800^{\circ} \mathrm{C}$, there is no advantage for an MR since both MREC and TREC tend to 1 . 
Two MR operating conditions were chosen for the analysis of the MR/GS integrated systems. A temperature of $550^{\circ} \mathrm{C}$ and hydrogen equilibrium partial pressure of 0.1 bar were considered for both; they differ for reaction pressure of 10 and 1.5 bar as reported in Table 3. The MR retentate compositions are reported, hereafter, in the figures related to the separation schemes (cases studies).

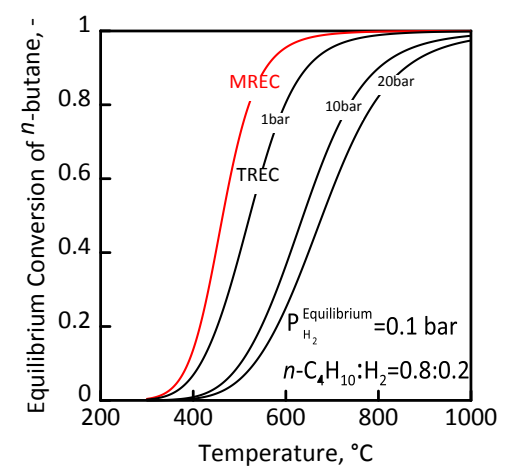

Figure 4. Equilibrium conversion of $n$-butane in a membrane reactor (MREC) and traditional reactor (TREC) as a function of the temperature for different feed pressures. Hydrogen equilibrium partial pressure: 0.1 bar. Initial molar composition $n$-butane: $\mathrm{H}_{2}=80: 20$.

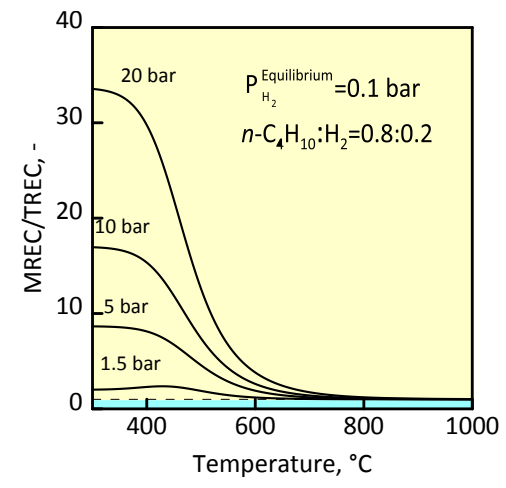

Figure 5. MREC/TREC ratio as a function of the temperature. Hydrogen equilibrium partial pressure: 0.1 bar. Initial molar composition $n$-butane: $\mathrm{H}_{2}=80: 20$.

\subsection{Plant Schemes for Butenes Production and Capture}

As mentioned in the previous sections, the Pd-Ag membrane property is that only the hydrogen permeates through it. This allows a pure hydrogen stream to be recovered in the permeate side of the MR. The permeation is promoted by a driving force equal to the difference in hydrogen partial pressure between the two membrane sides.

Table 3. Operating condition of the different membrane systems. Membrane reactor temperature $550{ }^{\circ} \mathrm{C}$. GS $=$ Gas Separation unit in each case study.

\begin{tabular}{|c|c|c|c|c|c|c|c|c|}
\hline \multirow{3}{*}{$\begin{array}{c}\text { Operating Parameters } \\
\text { Membrane reactor feed pressure } \\
\text { Membrane reactor feed molar composition }\end{array}$} & \multicolumn{2}{|c|}{ Case Study 1} & \multicolumn{2}{|c|}{ Case Study 2} & \multicolumn{2}{|c|}{ Case Study 3} & \multicolumn{2}{|c|}{ Case Study 4} \\
\hline & \multicolumn{4}{|c|}{10 bar } & \multicolumn{4}{|c|}{1.5 bar } \\
\hline & \multicolumn{2}{|c|}{$n-\mathrm{C}_{4} \mathrm{H}_{10}: \mathrm{N}_{2}=50: 50$} & \multicolumn{2}{|c|}{$n-\mathrm{C}_{4} \mathrm{H}_{10}: \mathrm{H}_{2}=80: 20$} & \multicolumn{2}{|c|}{$n-\mathrm{C}_{4} \mathrm{H}_{10}: \mathrm{N}_{2}=50: 50$} & \multicolumn{2}{|c|}{$n-\mathrm{C}_{4} \mathrm{H}_{10}: \mathrm{N}_{2}=50: 50$} \\
\hline Gas separation-Feed pressure to GS1 & \multicolumn{2}{|c|}{10 bar } & \multicolumn{2}{|c|}{10 bar } & \multicolumn{2}{|c|}{15 bar } & \multicolumn{2}{|c|}{10 bar } \\
\hline Separation stages & $\theta$ & $\phi$ & $\theta$ & $\phi$ & $\theta$ & $\phi$ & $\theta$ & $\phi$ \\
\hline GS1 & 50 & 10 & 580 & 5 & 10 & 15 & 20 & 10 \\
\hline GS2 & 2.5 & 10 & 0.5 & 10 & 10 & 10 & 0.1 & 5 \\
\hline GS3 & 2.5 & 10 & 0.57 & 10 & 0.25 & 15 & - & - \\
\hline GS4 & - & - & 25 & 2 & - & - & - & - \\
\hline
\end{tabular}


The MR retentate thus contains all the reaction products, the unconverted reactants and the eventual inert gases. This stream was fed to a multistage membrane system for the separation and recovery of the different components. Four case studies were explored (Table 3): MR was always operated at $550{ }^{\circ} \mathrm{C}$ and for Case Studies 1 and 2 at 10 bar, whereas for Case Studies 3 and 4 at 1.5 bar (see Al Megren et al. [23]). Each case study was constituted by three or four GS units and differed from the others for the operating conditions. Table 3 summarizes, beyond the MR operating conditions, the conditions of the membrane gas separation units expressed as permeation number and pressure ratio. Each GS unit contained polymeric membranes suitable for a defined separation. Table 4 reports permeance and selectivity of the membranes considered in this work for the different species involved. Matrimid is suitable for the separation of hydrogen from the rest of the stream. PTMSP indeed is known to be selective toward butane; therefore, it was used for the separation of paraffins-olefins. For the PSf membrane, only hydrogen, nitrogen, $\mathrm{C}_{3} \mathrm{H}_{8}$ and $\mathrm{C}_{4} \mathrm{H}_{10}$ permeance values were reported in the literature. In analogy, for PSM- $\mathrm{Ag}^{+}$membranes, only $1-\mathrm{C}_{4} \mathrm{H}_{8}, \mathrm{C}_{4} \mathrm{H}_{10}$ and $1,3-\mathrm{C}_{4} \mathrm{H}_{6}$ permeance values were reported. The remaining separation properties were set on the basis of separation properties of similar species. Generally, the permeance values of these membranes are comparable with the ones of other membranes used for other separations.

Table 4. Polymeric membrane properties in terms of permeance $\left(\mathrm{nmol} \cdot \mathrm{m}^{-2} \cdot \mathrm{s}^{-1} \cdot \mathrm{Pa}^{-1}\right)$ and selectivity.

\begin{tabular}{|c|c|c|c|c|c|c|c|c|}
\hline \multirow[b]{2}{*}{ Species } & \multicolumn{2}{|c|}{ Matrimid $[26,33,34]$} & \multicolumn{2}{|c|}{ PTMSP [27] } & \multicolumn{2}{|c|}{ PSf [35] } & \multicolumn{2}{|c|}{$\mathrm{PSM}^{-\mathrm{Ag}^{+}[28]}$} \\
\hline & Permeance & $\begin{array}{l}\text { Selectivity } \\
\mathrm{H}_{2} / i \text {-Specie }\end{array}$ & Permeance & $\begin{array}{c}\text { Selectivity } \\
n-\mathrm{C}_{4} \mathrm{H}_{10} / i \text {-Specie }\end{array}$ & Permeance & $\begin{array}{l}\text { Selectivity } \\
\mathrm{H}_{2} / i \text {-Specie }\end{array}$ & Permeance & $\begin{array}{c}\text { Selectivity } \\
\text { butenes/i-Specie }\end{array}$ \\
\hline $\mathrm{H}_{2}$ & 51.7 & 1 & 725 & 38.8 & 3.34 & 1 & 5.6 & 5000 \\
\hline $\mathrm{N}_{2}$ & 2.01 & 26 & 1020 & 27.5 & 0.83 & 4 & 5.6 & 5000 \\
\hline $\mathrm{CH}_{4}$ & 2.01 & 26 & 1020 & 27.5 & 0.83 & 4 & 5.6 & 5000 \\
\hline $\mathrm{C}_{2} \mathrm{H}_{6}$ & 0.20 & 258 & 3660 & 7.7 & 0.83 & 4 & 5.6 & 5000 \\
\hline $\mathrm{C}_{2} \mathrm{H}_{4}$ & 2.01 & 26 & 3660 & 7.7 & 0.83 & 4 & 28,200 & 1 \\
\hline $\mathrm{C}_{3} \mathrm{H}_{8}$ & 0.088 & 586 & 9240 & 3.1 & 0.016 & 200 & 5.6 & 5000 \\
\hline $\mathrm{C}_{3} \mathrm{H}_{6}$ & 0.20 & 258 & 9240 & 3.1 & 0.016 & 200 & 28,200 & 1 \\
\hline trans- $2-\mathrm{C}_{4} \mathrm{H}_{8}$ & 0.201 & 258 & 16,600 & 1.7 & 0.004 & 800 & 28,200 & 1 \\
\hline cis-2- $\mathrm{C}_{4} \mathrm{H}_{8}$ & 0.201 & 258 & 31,300 & 0.9 & 0.004 & 800 & 28,200 & 1 \\
\hline $1-\mathrm{C}_{4} \mathrm{H}_{8}$ & 0.129 & 401 & 20,100 & 1.4 & 0.004 & 800 & 28,200 & 1 \\
\hline iso- $\mathrm{C}_{4} \mathrm{H}_{8}$ & 0.129 & 401 & 20,100 & 1.4 & 0.004 & 800 & 28,200 & 1 \\
\hline$n-\mathrm{C}_{4} \mathrm{H}_{10}$ & 0.088 & 586 & 28,200 & 1 & 0.004 & 800 & 5.6 & 5000 \\
\hline iso- $\mathrm{C}_{4} \mathrm{H}_{10}$ & 0.027 & 1900 & 10,800 & 2.6 & 0.004 & 800 & 5.6 & 5000 \\
\hline $1,3-\mathrm{C}_{4} \mathrm{H}_{6}$ & 0.20 & 258 & 18,800 & 1.5 & 0.004 & 800 & 14,100 & 2 \\
\hline
\end{tabular}

\subsection{Case Study 1}

Figure 6 shows the flow sheet of Case Study 1. An equimolecular $n$-butane/nitrogen mixture was fed to the MR operated at $550{ }^{\circ} \mathrm{C}, 10$ bar for feed and a permeate pressure of 0.1 bar. In these circumstances, hydrogen recovery in the permeate was $95.2 \%$. The GS system had three membrane gas separation devices in a cascade configuration and the MR retentate pressure of 10 bar was used to promote permeation in all GS units. The permeates were recovered at atmospheric pressure. As mentioned, the pressure drops in the polymeric membrane units were negligible [29].

First (GS1) and second (GS2) separation units were equipped with membranes selective toward non-condensable species $\left(\mathrm{H}_{2}, \mathrm{~N}_{2}\right.$, etc.): PSf [35] and Matrimid [33,34] membranes, respectively. A permeate stream with high light species concentration was recovered owing to the high selectivity of the membrane. Moreover, the GS1 operating conditions (permeation number of 50 and pressure ratio of 10) were adjusted for maximizing the concentration of the non-condensable species such as nitrogen $\left(\mathrm{N}_{2}\right.$ molar concentration of $\left.72.17 \%\right)$ in the permeate. This allowed the butenes in the retentate side to be concentrated from $19.56 \%$ to $26.18 \%$ with a stage cut of $25.5 \%$. The latter was then fed to a second membrane gas separation device (GS2). Matrimid membranes show a different selectivity (Table 4) than PSf toward non-condensable gases $\left(\mathrm{N}_{2} / \mathrm{C}_{4}\right.$ and $\mathrm{H}_{2} / \mathrm{N}_{2}$ selectivity is 200 and 4, respectively); therefore, it recovers in the permeate almost all of the hydrogen present in the feeds, increasing the concentration of hydrocarbons in the retentate (stage cut of 55.9\%). As third separation stage, a membrane unit with a mixed matrix membrane $\left(\mathrm{PSM}-\mathrm{Ag}^{+}\right)$[28] was considered for 
olefins/paraffins separation. The high selectivity of the olefins and di-olefins (as butadiene) produced a permeate stream rich in butenes isomers with a stage cut of $40.07 \%$. In addition, owing to the high selectivity (butenes / $n$-butane of 5000), the olefins recovery was $61.4 \%$ with a butenes concentration in the permeate stream of $91.95 \%$ and butadiene of $7.55 \%$.

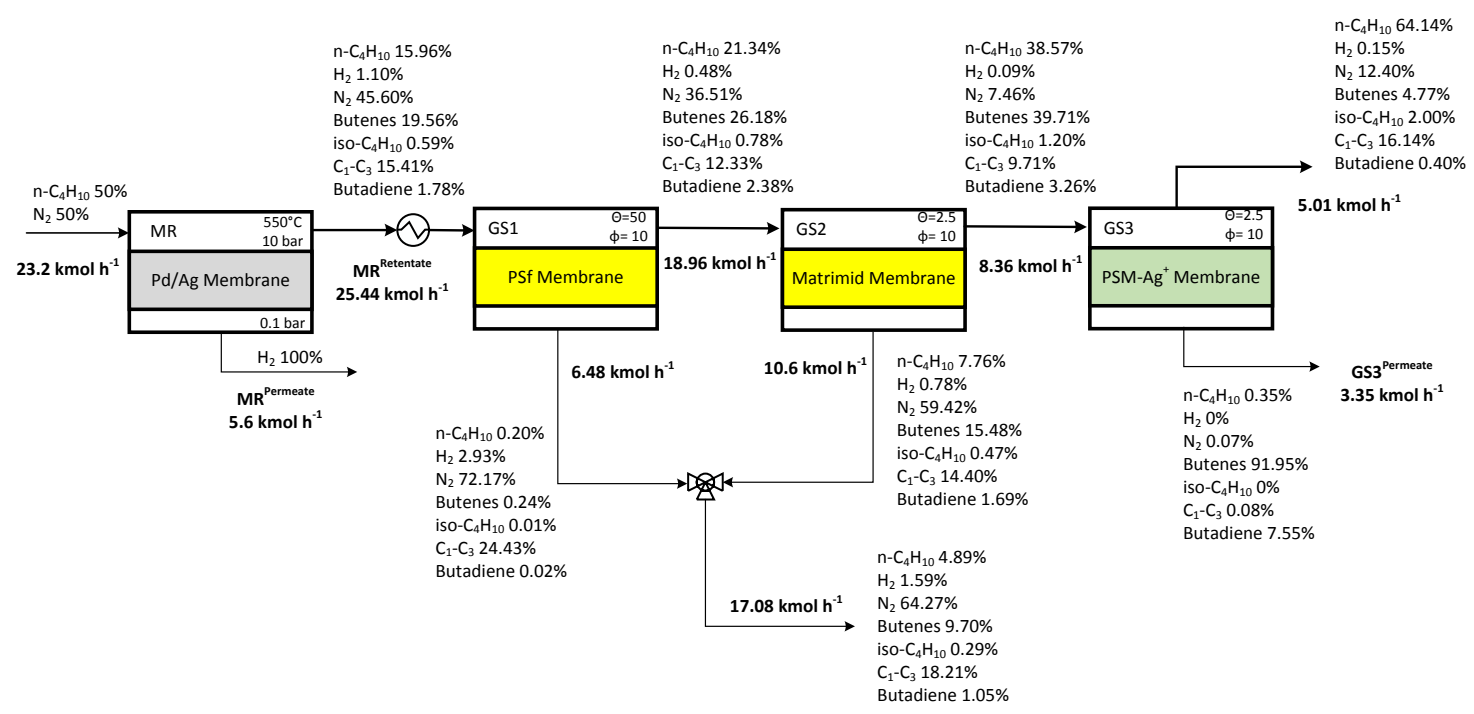

Figure 6. Case Study 1: Flow sheet, membrane units operating conditions and stream molar concentration.

\subsection{Case Study 2}

Figure 7 shows the flow sheet of Case Study 2. The MR was operated, similarly to Case Study 1, but with a different feed mixture, $n$-butane:hydrogen $=80: 20$ as in [36]. Analogously to Case Study 1 , the MR retentate stream was fed to the membrane separation system, after being cooled down to $50{ }^{\circ} \mathrm{C}$.

A Matrimid membrane unit (Table 4) was used in the first stage for recovering hydrogen and methane from hydrocarbons, retained in the retentate. Different from Case Study 1, here both retentate and permeate of GS1 were further treated. The GS1 was operated with a pressure ratio of 5 to maintain the pressure in the permeate stream (stage-cut of $12.75 \%$ ) at 2 bar necessary for the permeation of hydrocarbons through PTMSP membranes [27] in GS4. This separation stage allowed us to recover and concentrate hydrocarbons in the permeate reaching a $\mathrm{C}_{4}$ molar concentration of $59.28 \%$ with $42.31 \%$ of butenes with a stage-cut of $34.2 \%$.

The retentate stream of GS1, mainly constituted of hydrocarbons, was fed into a series of two membrane gas separation units, GS2 and GS3. PTMSP (Table 4) membranes were used in each unit. The scope of this cascade separation was to improve the hydrocarbons concentration and recovery. GS2 resulted in a rich $\mathrm{C}_{4}$ stream to be recovered at the permeate side with a molar concentration of $85.94 \%$ and stage cut of $51.1 \%$, when the permeation number was 0.5 and pressure ratio was 10 . The retentate stream of GS2, still rich in hydrocarbons, was fed to the last membrane gas separation unit, GS3 (stage cut of 55.1\%). A pressure ratio 10 and a permeation number 0.57 were selected for improving butenes recovery. Under these circumstances it was possible to obtain a $\mathrm{C}_{4}$ concentration in the permeate of $74.62 \%$ with $49.67 \%$ of butenes. Combining the permeate streams of GS2, GS3 and GS4, the total $\mathrm{C}_{4}$ olefins concentration was $55.5 \%$ with a high recovery, $87.1 \%$, and a high $\mathrm{C}_{4}$ recovery of $88.5 \%$. 


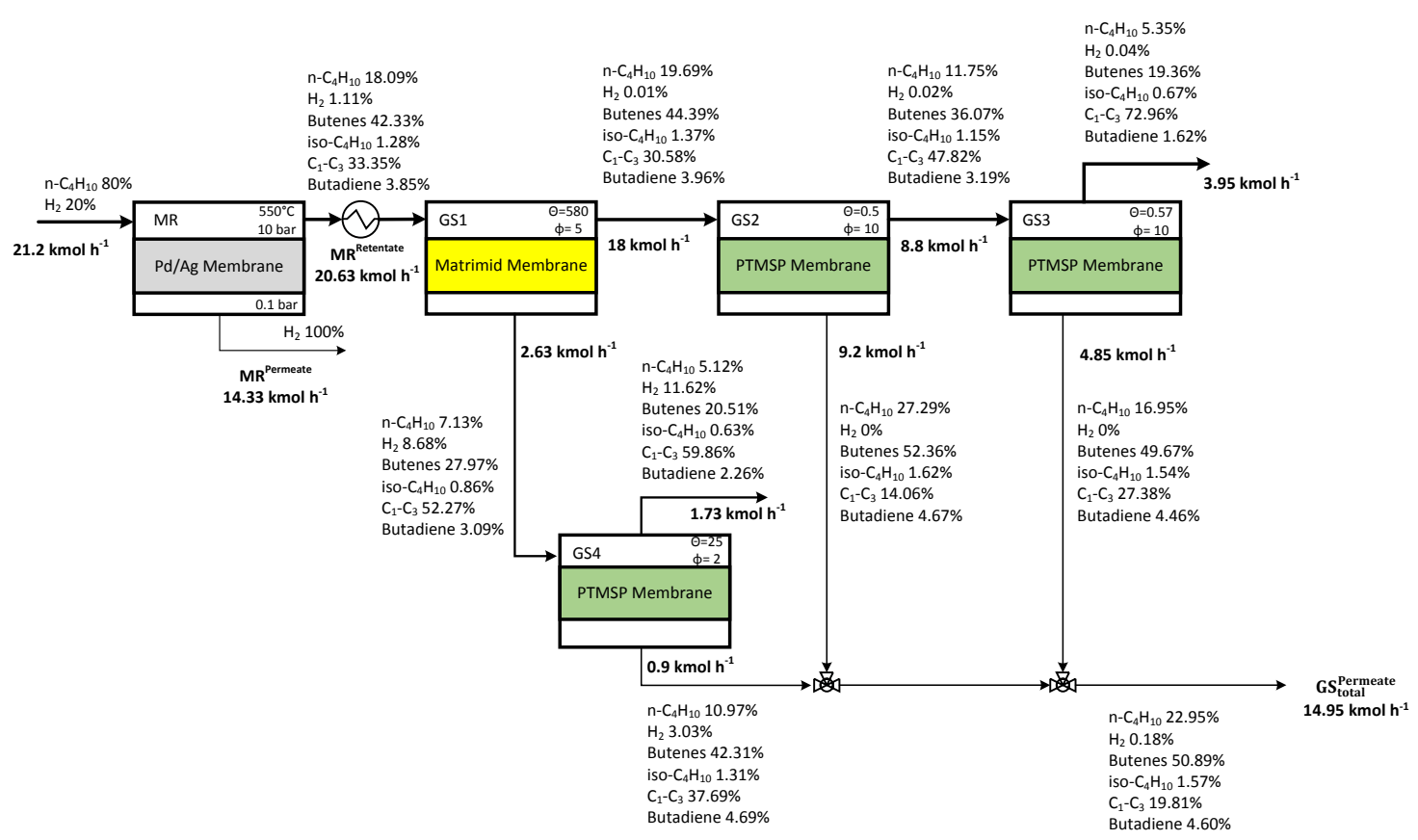

Figure 7. Case Study 2: Flow sheet, membrane units operating conditions and stream molar concentration.

\subsection{Case Study 3}

For Case Study 3, the MR operating conditions were unchanged with respect to Case Studies 1 and 2 except for the reaction pressure, which was 1.5 bar, a typical pressure used in a traditional reactor for butenes production from butane [3]. The MR feed mixture was the same as for Case Study 1, an equimolecular stream of nitrogen and $n$-butane. Owing to the low reaction pressure, the hydrogen recovery was lower (66.2\%) than Case Studies 1 and 2. The MR retentate stream contained large amounts of non-condensable gases (ca. 50\%) needing separation. For this purpose, it was fed into a GS unit with PSf membranes, after being compressed to 15 bar and cooled to $50{ }^{\circ} \mathrm{C}$. The presence of PSf membranes combined with the high fraction of hydrogen and nitrogen in the feed of GS1 and the high pressure ratio allowed a higher total hydrogen and nitrogen recovery of 95.9\% (Figure 8).

A further concentration of this stream, with consequent recovery of the hydrocarbons, was done by feeding this stream to a second membrane gas separation device with PSf membranes, after re-compression to 15 bar. The GS2 permeation number, pressure ratio and stage cut were 10, 10 and $87.57 \%$, respectively. The pressure ratio of 10 allowed recovering the permeate at 1.5 bar with the possibility of recycling this stream rich in nitrogen to the inlet of the reactor, but, although interesting, this configuration was not further investigated in this work. The retentate stream was richer in hydrocarbons compared to the GS1 permeate and after being mixed with the retentate stream of GS1 (Figure 8), was fed to stage GS3 (stage cut of 39.2\%) for hydrocarbons separation. Both streams were at 15 bar. In this latter gas separation unit, with a PTMSP membrane, the feed stream contained $39.8 \%$ butenes and ca. $77.11 \% \mathrm{C}_{4}$ and it was possible to recover ca. $38.7 \%$ of $\mathrm{C}_{4}$ olefins at $43.31 \%$ molar, operating at pressure ratio of 15 and permeation number of 0.25 . 


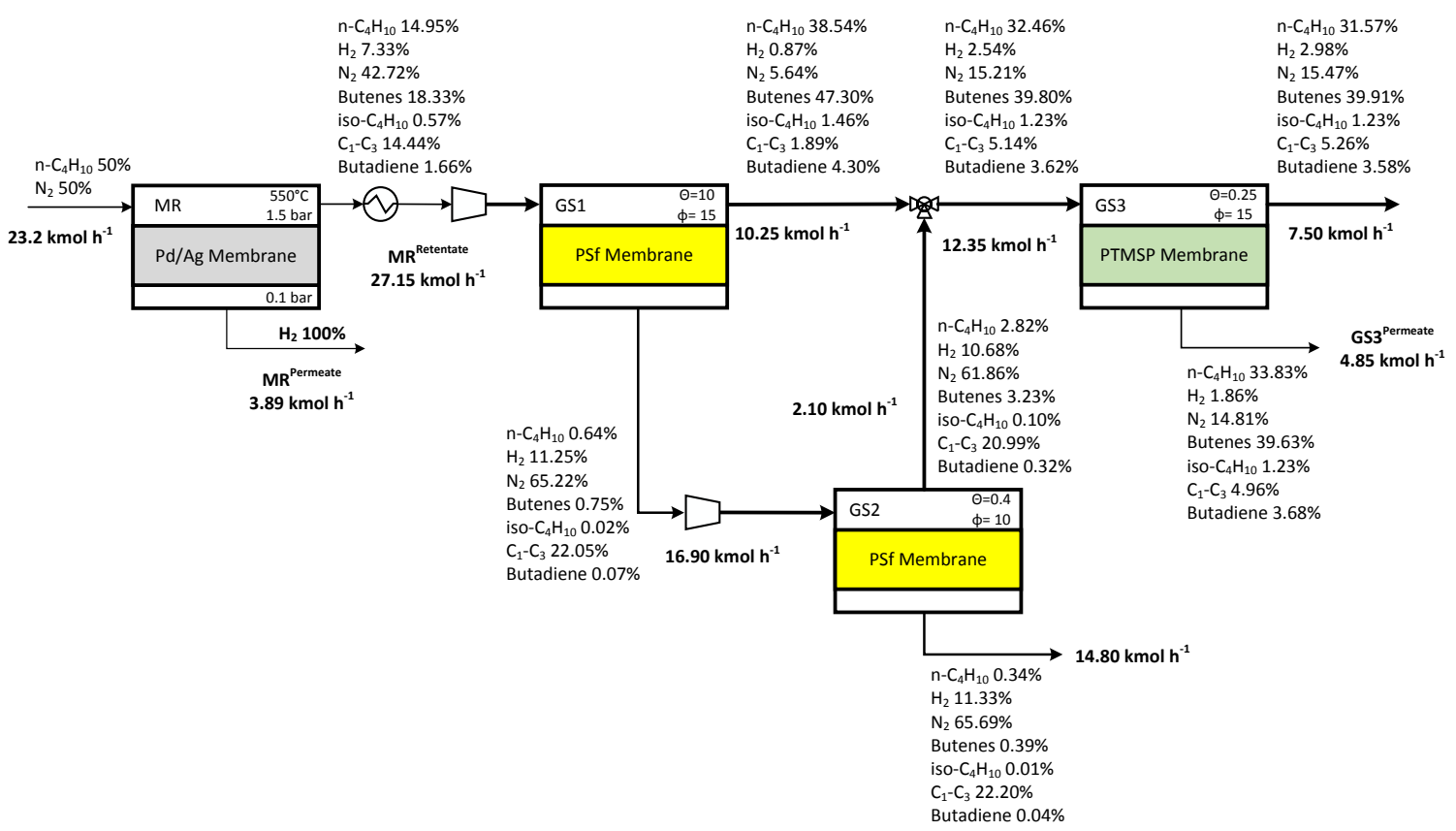

Figure 8. Case Study 3: Flow sheet, membrane units operating conditions and stream molar concentration.

\subsection{Case Study 4}

Case Study 4 differs from the previous cases for the presence of a flash separation (traditional unit operation) used for separating the MR retentate stream (Figure 9). The MR stream fed to the separation stage was the same as for of Case Study 3. It was operated at $550{ }^{\circ} \mathrm{C}$ and 1.5 bar and the permeate pressure was 0.1 bar. The feed stream was a $n$-butane/nitrogen equimolecular mixture. In particular, the MR retentate stream was fed to a heat exchanger and then compressed to 10 bar and cooled down to $0{ }^{\circ} \mathrm{C}$. This condition allowed hydrocarbons condensation and thus their recovery in a liquid fraction, whereas hydrogen and nitrogen were recovered in the gaseous phase with a molar concentration of $73.27 \%$. The liquid stream was hydrocarbons rich $\left(\mathrm{C}_{4} \mathrm{ca}\right.$. $\left.87.37 \%\right)$. Both streams were heated and fed to different membrane gas separation units for further separation (Figure 9). PSf membranes were used in GS1 for hydrogen and nitrogen separation; this resulted in a retentate stream rich in hydrocarbon (ca. $89.5 \%$ of $\left.\mathrm{C}_{4}\right)$, the permeate mainly consisted of $\mathrm{N}_{2}$ and $\mathrm{H}_{2}(68.53 \%$ and $11.82 \%$, respectively). The GS1 was operated at a pressure ratio of 10 and permeation number of 20 (stage cut of $90.2 \%$ ). The retentate was then mixed with the vaporized liquid coming from the flash to be treated in a second membrane gas separation device, GS2 (stage cut 12.88\%) with PTMSP membranes. This unit was operated at pressure ratio of 5 and permeation number of 0.1 with $C_{4}$ recovery of $14 \%$ and butenes concentration of $47.16 \%$.

\subsection{Case Studies Summary}

Table 5 reports the $\mathrm{C}_{4}$ concentration and recovery of the four case studies. Owing to the higher selectivity of PSM- $\mathrm{Ag}^{+}$membrane, Case Study 1 showed a product stream with a high olefins concentration, $99.5 \%$. Case Study 2 showed a $\mathrm{C}_{4}$ recovery of $88.5 \%$ but lower $\mathrm{C}_{4}$ molar concentration compared to the Case Study 1. Instead, Case Study 4 allowed obtaining a rich $C_{4}$ stream (99.3\%) with lower $\mathrm{C}_{4}$ recovery $(14 \%)$. 


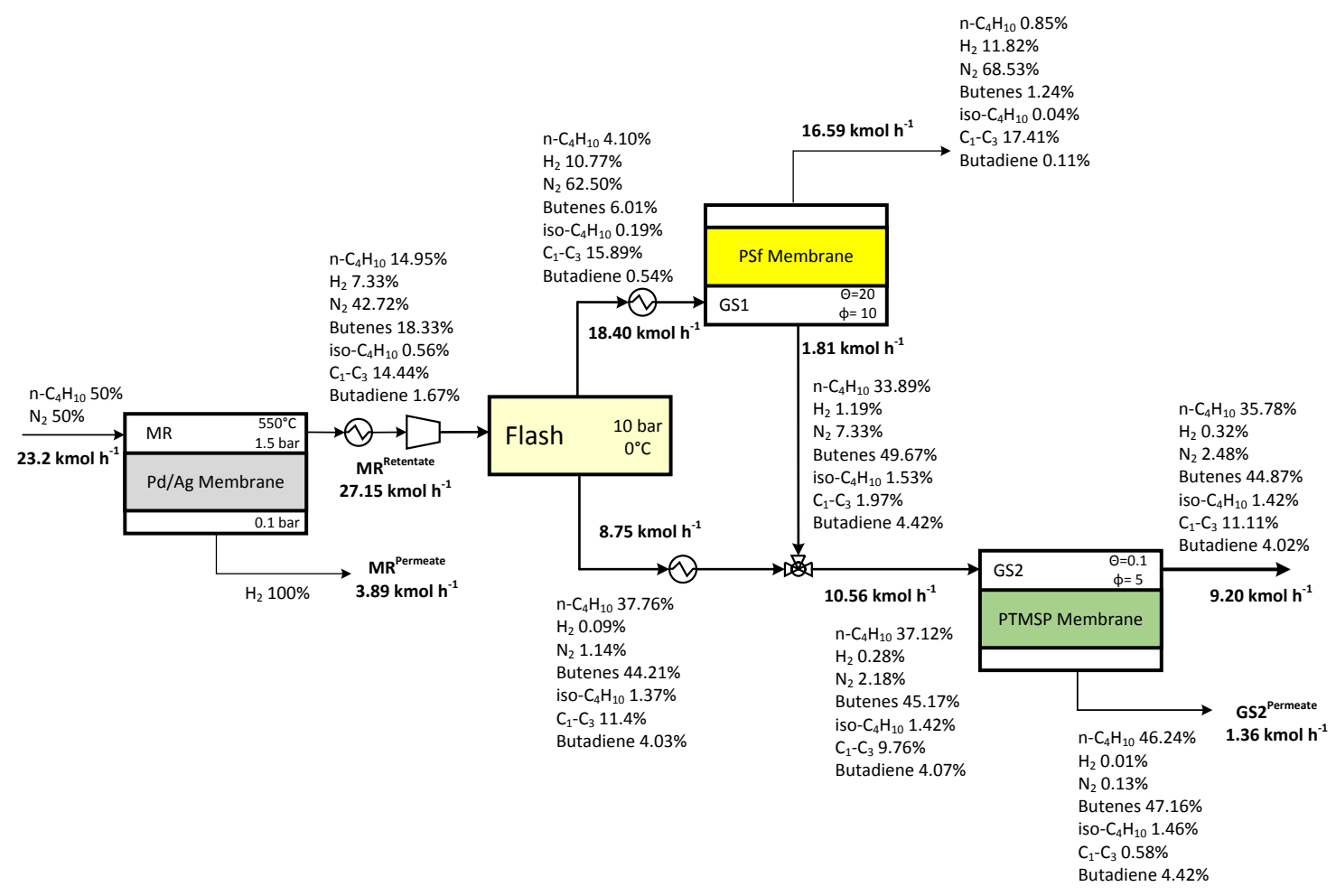

Figure 9. Case Study 4: Flow sheet, membrane units operating conditions and stream molar concentration.

Table 5. Butenes recovery and concentration of the different case studies.

\begin{tabular}{|c|c|c|c|c|c|c|c|c|}
\hline & \multicolumn{2}{|c|}{ Case Study 1} & \multicolumn{2}{|c|}{ Case Study 2} & \multicolumn{2}{|c|}{ Case Study 3} & \multicolumn{2}{|c|}{ Case Study 4} \\
\hline Feed molar ratio & \multicolumn{2}{|c|}{$n-\mathrm{C}_{4} \mathrm{H}_{10}: \mathrm{N}_{2}=50: 50$} & \multicolumn{2}{|c|}{$n-\mathrm{C}_{4} \mathrm{H}_{10}: \mathrm{H}_{2}=80: 20$} & \multicolumn{2}{|c|}{$n-\mathrm{C}_{4} \mathrm{H}_{10}: \mathrm{N}_{2}=50: 50$} & \multicolumn{2}{|c|}{$n-\mathrm{C}_{4} \mathrm{H}_{10}: \mathrm{N}_{2}=50: 50$} \\
\hline $\mathrm{C}_{4}$ recovery, $\%$ & $\frac{\mathrm{GS}_{C_{4}}^{\text {Permeate }}}{\mathrm{MR}_{\mathrm{C}_{4}}^{\text {Retentate }}}$ & $34.7 \%$ & $\frac{\mathrm{GS}_{\text {total, }}^{\text {Perme }}}{\mathrm{CR}_{\mathrm{C}_{4}}^{\text {Retentate }}}$ & $88.5 \%$ & $\frac{\mathrm{GS}_{3}{ }_{\mathrm{C}_{4}}^{\text {Permeate }}}{\mathrm{MR}_{\mathrm{C}_{4}}^{\text {Retentate }}}$ & $39.4 \%$ & $\frac{\mathrm{GS}_{C_{4}}^{\text {Permeate }}}{\mathrm{MR}_{\mathrm{C}_{4}}^{\text {Retentate }}}$ & $14 \%$ \\
\hline $\begin{array}{c}\mathrm{C}_{4} \text { molar } \\
\text { concentration, \% }\end{array}$ & $\frac{\mathrm{GS}_{3}{ }_{\mathrm{C}_{4}}^{\text {Permeate }}}{\mathrm{GS}^{\text {Permeate }}}$ & $99.9 \%$ & $\frac{\mathrm{GS}_{\text {total, }}^{\text {Permeate }}}{\mathrm{GS}_{\text {total }}^{\text {Perte }}}$ & $80 \%$ & $\frac{\mathrm{GS}_{3}{ }_{\mathrm{C}_{4}}^{\text {Permeate }}}{\mathrm{GS}^{{ }^{1}} 3^{\text {Permeate }}}$ & $78.4 \%$ & $\frac{\mathrm{GS}_{C_{4}^{4}}^{\text {Permeate }}}{\mathrm{GS}^{{ }^{4} \text { ermmeate }}}$ & $99.3 \%$ \\
\hline $\begin{array}{c}\mathrm{C}_{4} \text { olefins } \\
\text { recovery, \% }\end{array}$ & $\frac{\mathrm{GS}_{3}^{\text {Pormeatente }}}{\mathrm{MR}_{\text {Olefintaste }}^{\text {Retens }}}$ & $61.4 \%$ & $\frac{\mathrm{GS}_{\text {total, }}^{\text {Pelefefins }}}{\mathrm{MR}_{\text {Olefentate }}^{\text {Rete }}}$ & $87.1 \%$ & $\frac{\mathrm{GS3}_{3}^{\text {Olermeate }}}{\mathrm{MR}_{\text {Olefefins }}^{\text {Retete }}}$ & $38.7 \%$ & $\frac{\mathrm{GS2}_{\text {Olfermine }}^{\text {Permete }}}{\mathrm{MR}_{\text {Olefefins }}^{\text {Rete }}}$ & $12.9 \%$ \\
\hline $\begin{array}{l}\mathrm{C}_{4} \text { olefins molar } \\
\text { concentration, } \%\end{array}$ & $\frac{\mathrm{GS}_{3} 3_{\text {Olermeate }}^{\text {Pefins }}}{\text { GS3 }^{\text {Permeate }}}$ & $99.5 \%$ & $\frac{\mathrm{GS}_{\text {total, }}^{\text {Perefefins }}}{\mathrm{GS}_{\text {total }}^{\text {Permete }}}$ & $55.5 \%$ & $\frac{\mathrm{GS} 3^{\text {Permeate }}}{\text { GS3 }^{\text {Pefins }}}$ & $43.3 \%$ & $\frac{\mathrm{GS2}_{2}^{\text {POermeate }}}{\mathrm{GS}^{\text {Perme }}}$ & $51.6 \%$ \\
\hline Production rate, $\%$ & \multicolumn{2}{|c|}{$26.6 \%$} & \multicolumn{2}{|c|}{$44.9 \%$} & \multicolumn{2}{|c|}{$16.6 \%$} & \multicolumn{2}{|c|}{$5.5 \%$} \\
\hline
\end{tabular}

The production rate is defined as the ratio between the olefins recovered in the downstream of the system and $n$-butane fed to the MR. It defines the efficiency of the process in terms of the flow rate of olefins recovered with respect to the $n$-butane fed to the MR.

$$
\text { Production rate }=\frac{\text { Butenes recoved as permeates }}{n-\text { butane fed to Membrane Reactor }}
$$

The production rate was calculated referring to butenes recovered as products over $n$-butane fed into the system.

The production rate needs to be maximized to improve system efficiency. Owing to the higher butenes recovery compared to the other case studies, Case Study 2 is the best scheme with a production rate of $44.9 \%$. Instead, Case Study 4 , characterized by high $\mathrm{C}_{4}$ concentration, has a very low production rate $5.5 \%$.

Industry wants a high recovery (99\%) combined with a high concentration $(99 \%)$. This can be obtained by low temperature distillation (at high pressure). Membranes can help to improve this by reducing the energy consumption. 


\section{Conclusions}

In this work, an integrated membrane system for butenes production was proposed and investigated by means of a modeling analysis. The $n$-butane dehydroisomerization was considered to take place in a Pd-Ag membrane reactor able to promote conversion, meanwhile recovering a pure $\mathrm{H}_{2}$ stream in the permeate. A thermodynamics study revealed the operating conditions where the membrane reactor shows better performance than a traditional reactor. For instance, at $550{ }^{\circ} \mathrm{C}$ and $10 \mathrm{bar}$ and $0.1 \mathrm{bar}$ as reaction and permeate pressure, respectively, the membrane reactor equilibrium conversion was five times higher than that of a traditional reactor.

The membrane reactor retentate, rich in unconverted reactants, reaction products, inerts, etc. but poor in hydrogen, was post-treated in a multistage membrane separation system. Four different case studies were investigated, analyzing different options in terms of membranes used and operating conditions suitable to maximize a certain separation. Globally, a high butenes recovery corresponded to a lower $\mathrm{C}_{4}$ olefins concentration (55.5\%) with respect to Case Study 1, as in Case Study 2 with $C_{4}$ recovery of $88.5 \%$. In line with this conclusion, Case Study 4 exhibited a $\mathrm{C}_{4}$ concentration of $99.3 \%$ and lower $\mathrm{C}_{4}$ recovery (14\%). Owing to the high membrane selectivity in the GS3, Case Study 1 is the best in terms of olefins concentration (99.5\%). The Case Study 2 proved to be the best in terms of production rate, the ratio of olefins recovered as permeate and the $n$-butane fed to the integrated system.

Author Contributions: All authors equally contributed to the various aspects of the research and in writing and correcting the paper.

Conflicts of Interest: The authors declare no conflict of interest.

\section{Abbreviations}

\section{Acronyms}

FCC

GS

MR

MREC

PI

TR

TREC

Variables

A

$H$

K

$m$

$n$

$n_{0}$

$P$

$Q$

$T$

$x$

$x_{1}$

$x_{2}$

$z$

Greek letters

$\theta$

$\phi$
Fluidized catalytic cracking

Gas separator

Membrane reactor

Membrane reactor equilibrium conversion

Process intensification

Traditional reactor

Traditional reactor equilibrium conversion

Surface area, $\mathrm{m}^{2}$

Enthalpy, $\mathrm{J} \mathrm{mol}^{-1}$

Equilibrium constant, -

Mole ratio, -

Mole number, -

Initial total mole, -

Pressure, bar

Volumetric flow rate, $\mathrm{m}^{3} \mathrm{~h}^{-1}$

Temperature, ${ }^{\circ} \mathrm{C}$

Molar fraction, -

Conversion dehydrogenation reaction, -

Conversion isomerization reaction, -

Fraction of hydrogen permeate, -

Permeation number, -

Feed/Permeate pressure ratio, - 


\section{References}

1. Research Agenda for Process Intensification Towards a Sustainable World of 2050. Available online: http://www.3me.tudelft.nl/fileadmin/Faculteit/3mE/Actueel/Nieuws/2011/docs/DSD_Research_ Agenda.pdf (accessed on 29 July 2016).

2. Ramshaw, C. The intensive for process intensification. In Proceedings of the 1st International Conference for Process Intensification in the Chemical Industry, Antwerp, Belgium, 6-8 December 1995.

3. Bender, M. An overview of industrial process for the production of olefins $\mathrm{C}_{4}$ hydrocarbons. ChemBioEng Rev. 2014, 1, 136-147.

4. Pirngruber, G.D.; Seshan, K.; Lercher, J.A. Dehydroisomerization of $n$-butane over Pt-ZSM5: II. Kinetic and Thermodynamics Aspect. J. Catal. 2000, 190, 134-137. [CrossRef]

5. Li, X.; Iglesia, E. Catalytic dehydroisomerization of n-alkanes to isoalkenes. J. Catal. 2008, 255, $134-137$. [CrossRef]

6. Scirè, S.; Burgio, G.; Crisafulli, C.; Minicò, S. Dehydroisomerization of $n$-butane over H-Y zeolite supported Pt and Pt, Sn catalyst. App. Catal. A 2004, 274, 151-157. [CrossRef]

7. Pirngruber, G.D.; Seshan, K.; Lercher, J.A. Dehydroisomerization of $n$-butane over Pt-ZSM5 (I): Effect of the metal loading and acid site concentration. J. Catal. 1999, 186, 188-200. [CrossRef]

8. Hamid, S.B.D.A.; Lambert, D.; Derouane Eric, G. Dehydroisomerisation of $n$-butane over $(\mathrm{Pt}, \mathrm{Cu}) / \mathrm{H}-\mathrm{TON}$ catalysts. Catal. Today 2000, 63, 237-247. [CrossRef]

9. Stankiewicz, A.; Moulijn, J. A Process intensification: Transforming chemical engineering. Chem. Eng. Prog. 2000, 96, 22-23. [CrossRef]

10. Stankiewicz, A.; Moulijn, J.A. Process Intensification. Ind. Eng. Chem. Res. 2002, 41, 1920-1924. [CrossRef]

11. Weyten, H.; Luyten, J.; Keizer, K.; Willems, L.; Leysen, R. Membrane performance: The key issues for dehydrogenation reactions in a catalytic membrane reactor. Catal. Today 2000, 56, 3-11. [CrossRef]

12. Van der Bergh, J.; Gucuyener, C.; Gascon, J.; Kapteijn, F. Isobutane dehydroisomerization in a DDR3 zeolite membrane reactor. Chem. Eng. J. 2011, 166, 368-377. [CrossRef]

13. Yanglong, G.; Guanzhong, L.; Yunsong, W.; Ren, W. Preparation and characterization of Pd-Ag/ceramic composite membrane and application to enhancement of catalytic dehydrogenation of isobutane. Sep. Purif. Technol. 2003, 32, 271-279.

14. Babak, V.N.; Babak, T.B.; Zakiev, S.E.; Kholpanov, L.P. Theoretical study of hydrocarbon dehydrogenation at high temperatures. Theor. Found. Chem. Eng. 2009, 43, 74-87. [CrossRef]

15. Sanchez, J.; Tsotsis, T.T. Catalytic Membranes and Membrane Reactors; Wiley-VCH: Weinheim, Germany, 2002.

16. Casanave, D.; Giroir-Fendler, A.; Sanchez, J.; Loutaty, R.; Dalmon, J.A. Control of transport properties with a microporous membrane reactor to enhance yields in dehydrogenation reactions. Catal. Today 1995, 25, 309-314. [CrossRef]

17. van Dyk, L.; Miachon, S.; Lorenzen, L.; Torres, M.; Fiaty, K.; Dalmon, J.-A. Comparison of microporous MFI and dense Pd membrane performances in an extractor-type CMR. Catal. Today 2003, 82, 167-177. [CrossRef]

18. Liang, W.; Huges, R. The catalytic dehydroisomerization of isobutane to iso-butene in a palladium/silver composite membrane reactor. Catal. Today 2005, 104, 74-87. [CrossRef]

19. Sznejer, G.; Sheintuch, M. Application of a carbon membrane reactor for dehydrogenation reactions. Chem. Eng. Sci. 2004, 59, 2013-2021. [CrossRef]

20. Marigliano, G.; Barbieri, G.; Drioli, E. Equilibrium conversion for a Pd-based membrane reactor. Dependence on the temperature and pressure. Chem. Eng. Process. 2003, 42, 231-236. [CrossRef]

21. Brunetti, A.; Caravella, A.; Drioli, E.; Barbieri, G. Process intensification by membrane reactors: High temperature water gas shift reaction as single stage for syngas upgrading. Chem. Eng. Technol. 2012, 35, 1-12. [CrossRef]

22. Barbieri, G.; Marigliano, G.; Perri, G.; Drioli, E. Conversion-temperature diagram for a palladium membrane reactor. Analysis of an endothermic reaction: methane steam reforming. Ind. Eng. Chem. Res. 2001, 40, 2017-2026. [CrossRef]

23. Al-Megren, H.A.; Barbieri, G.; Mirabelli, I.; Brunetti, A.; Drioli, E.; Al-Kinany, M.C. Direct conversion of n-butane to iso-butene in a membrane reactor: Thermodynamics Analysis. Ind. Eng. Chem. Res. 2013, 52, 10380-10386. [CrossRef] 
24. Barbieri, G.; Brunetti, A.; Caravella, A.; Drioli, E. Medium/high temperature water gas shift reaction in a Pd-Ag membrane reactor: An experimental investigation. RSC Adv. 2011, 1, 651-661. [CrossRef]

25. Pinnau, I.; Toy, L.G. Transport of organic vapours through poly(1-trimethylsilyl-1-propyne). J. Membr. Sci. 1996, 116, 199-209. [CrossRef]

26. Sakellaropoulos, G.P.; Plaggesis, H.; Koops, G.H.; Makhlouf, M. Membrane Separation of Olefins from FCC Naphtha and Gases for Production of Reformulated Gasoline. Contract JOE3-CT97-0052. Available online: http://cordis.europa.eu/documents/documentlibrary/50781711EN6.pdf (accessed on 29 July 2016).

27. Yang, J.-S.; Hsiue, G.-H. C 4 olefin/paraffin separation by poly[(1-trimethylsilyl-1-propyne]-graft-poly(acrylic acid)- $\mathrm{Ag}^{+}$complex membranes. J. Membr. Sci. 1996, 111, 27-38. [CrossRef]

28. Adachi, K.; Hu, W.; Matsumoto, H.; Ito, K.; Tanioka, A. Permeation of $n$-butane, 1-butane and 1,3-butadiene through anhydrated $\mathrm{Ag}^{+}$-doped perfluorocarbon-type ion-exchange membranes. Polymers 1998, 181, 2315-2323. [CrossRef]

29. Wu, J.; Chen, V. Shell-side mass transfer performance of randomly packed hollow fiber modules. J. Membr. Sci. 2000, 172, 59-74.

30. Adhikari, S.; Fernando, S. Hydrogen membrane separation techniques. Ind. Eng. Chem. Res. 2006, 45, 874-881. [CrossRef]

31. Inaba, M.; Murata, K.; Saito, M.; Takahara, I.; Mimura, N.; Hamada, H.; Kurata, Y. Dehydrogenation and isomerization of $n$-butane or isobutane over Cr catalyst supported on zeolites. Catal. Lett. 2002, 84, 273-279. [CrossRef]

32. Brunetti, A.; Scura, F.; Barbieri, G.; Drioli, E. Membrane technologies for $\mathrm{CO}_{2}$ separation. J. Membr. Sci. 2010, 359, 115-125. [CrossRef]

33. Falbo, F.; Tasselli, F.; Brunetti, A.; Drioli, E.; Barbieri, G. Polyimide hollow fibre membranes for $\mathrm{CO}_{2}$ separation from wet gas mixture. Braz. J. Chem. Eng. 2014, 31, 1023-1034. [CrossRef]

34. Koros, W.J.; Wo, D.G. Elevated temperature application of polymer hollow-fibre membranes. J. Membr. Sci. 2001, 181, 157-166. [CrossRef]

35. Yampolskii, Y.; Pinnau, I.; Freeman, B. Materials Science of Membrane for Gas and Vapour Separation; Jhon Wiley \& sons: West Sussex, UK, 2006.

36. Pirngruber, G.D.; Seshan, K.; Lercher, J.A. A direct conversion of $n$-butane to iso-butene over Pt-ZSM5: II. Kinetic and thermodynamic aspect. J. Catal. 2000, 192, 338-351. [CrossRef] 